\title{
Religious Perspectives on Death by Neurological Criteria: The Role of the Hospital Chaplain
}

\author{
Angela Hays Shapshak * (i)
}

@ 2021 Springer Science+Business Media, LLC, part of Springer Nature and Neurocritical Care Society

The concept of brain death, otherwise known as death by neurological criteria (DNC), occupies a unique position in clinical practice. Unlike most other clinical entities, the process of diagnosing death has implications that extend beyond the practice of medicine, influencing cultural, spiritual, legal, and political spheres. Historically, societal practices regarding the determination of death have been driven by religious leaders; Maimonides, a medieval Torah scholar who defined death as the absence of respiration, is one prominent example [1]. Other religious leaders included lack of cardiac activity as a requirement; together, the absence of cardiac and respiratory function formed the underpinning of the conventional understanding of death for centuries.

However, with the advent of modern critical care and organ-support technologies, the cardiopulmonary definition of death has become obsolete. The concept of DNC was pioneered in the 1960s, and the legal foundation for declaration of death by neurological criteria was established in the United States in 1981 with the passage of the Uniform Declaration of Death Act [2]. Despite broad acceptance within the international medical community, bioethicists and legal scholars continue to debate the rationale for equating DNC with the death of the person [3-5]. Critics have cited these ongoing philosophical debates as an argument against broad acceptance of $\mathrm{DNC}$ as a legal and ethical standard. Recently, a handful of high-profile cases have drawn considerable media

\footnotetext{
*Correspondence: ashapshak@uabmc.edu

Division of Cerebrovascular Diseases, Departments of Neurology and Anesthesiology, University of Alabama at Birmingham, Birmingham, $A L, U S A$
}

This article is related to the Original work available at https://link.springer. com/article/10.1007/s12028-021-01252-x.

\section{Springer}

attention, bringing some of this controversy into public discourse [5-9].

Under these circumstances, it is unsurprising that public understanding and acceptance of DNC remains poor [10]. Mainstream media coverage of the topic is rife with misinformation, and portrayals of brain death in fiction are woefully inaccurate [11-13]. One survey of Ohio residents indicated that only $33.7 \%$ of patients understood that individuals who are declared brain dead are legally dead [14]. This lack of understanding has important implications both for public policy and the provision of clinical care. A lack of understanding of the concept of DNC, particularly the equivalency of DNC with death by cardiopulmonary criteria, has been associated with decisions against organ donation $[15,16]$. Furthermore, uncertainty surrounding the diagnosis and confusion about its implications have been identified as causes of significant emotional distress for families of patients undergoing a DNC evaluation [17, 18]. Often, families who object to organ donation and/or the diagnosis of DNC cite a perceived conflict with their religious beliefs; in some instances, these cases have resulted in legal challenges $[6,9,19]$.

In these situations, hospital chaplains play a key role as providers of spiritual support and counsel to the families of patients who have suffered a catastrophic injury. Despite this important responsibility, little is known about the perspectives of hospital chaplains on DNC. In this issue of Neurocritical Care, Lewis and Kitamura [20] report on the results from their survey of hospital chaplains, which was intended to assess respondents' knowledge, experiences, and opinions regarding DNC. The survey incorporated questions regarding chaplains' experiences with families who voiced religious objections to 
the declaration of DNC and allowed the opportunity for free-text responses.

Ultimately, 512 responses were collected, and several important findings emerged. Most notably, despite the fact that $97 \%$ of respondents reported personal involvement in DNC cases, only $52 \%$ were aware that a permanent loss of consciousness was a prerequisite. In contrast to surveys conducted on the lay populace, the majority of chaplains were aware that DNC is legally equivalent to cardiopulmonary death; this knowledge was associated with prior involvement in cases complicated by religious objections to DNC on the part of the family. Approximately half of the surveyed chaplains reported experience with families who voiced religious objections to DNC; interestingly, there was no association with employment in a state with a legal requirement to consider religious objections as opposed to a state without. Responses to the questions pertaining to the religious identification of families who objected to DNC suggested an overrepresentation among families of Jewish, Muslim, Hindu, and Buddhist patients; however, these data are potentially confounded by recall bias and would benefit from further study.

The majority of respondents affirmed the belief that patients who are declared brain dead are dead, and agreement with this statement was significantly correlated with board certification and with greater experience. It is worth noting that a sizable minority endorsed the opinion that all states should legally require hospitals to accommodate religious objections to DNC (30\%), that families should have the option to decline brain death evaluation (16\%), or that families should have the ability to choose whether organ support is withdrawn after a determination of DNC (14\%). Affirmation of these beliefs correlated with a lack of general knowledge about brain death.

As noted by the authors, the generalizability of these findings may be limited because of the fact that the vast majority of the respondents were Christian and identified as members of a single professional organization. Nevertheless, the results indicate that knowledge gaps exist within the study population. Because of their critical role as spiritual counselors and advisors for families of critically ill patients, chaplains are in a position to facilitate communication with health care providers and assist families who are coping with bereavement. Studies of communication in critically ill populations have identified inconsistent messaging as a source of stress and dissatisfaction for families [21]; similarly, a study of donor families has indicated that confusion surrounding the diagnosis of brain death exacerbated their emotional distress [17]. Furthermore, some authors have suggested that religious objections may occasionally result from distress surrounding the diagnosis or arise from conflict with the medical team rather than from deeply held religious beliefs [22]; this possibility was also raised by respondents to the Lewis and Kitamura [20] survey in free-text comments. Commenters also emphasized the need for greater understanding of religious perspectives on the part of the health care team as well as the need for consistent communication [20]. In a recent international consensus statement, the authors of the World Brain Death Project provided recommendations for managing conflicts with families, including proactive engagement with religious communities to avoid conflicts and the use of multidisciplinary teams, including spiritual care and religious leaders, during conversations regarding DNC [23]. These recommendations are supported by the data presented here. Enhanced engagement and collaboration with hospital chaplains and chaplaincy organizations will be necessary to align with these recommendations and improve the care of patients and their families.

\section{Author Contributions}

The author was responsible for writing and submitting the manuscript, and has reviewed and approved the final version as submitted.

\section{Source of Support}

No funding was provided for this work.

\section{Conflicts of interest}

AHS has received salary support from the National Institutes of Health and serves as an unpaid member of the advisory board for her local organ procurement organization.

Ethical Approval

This work was exempt from IRB review per institutional policy.

\section{Publisher's Note}

Springer Nature remains neutral with regard to jurisdictional claims in published maps and institutional affiliations.

Received: 4 April 2021 Accepted: 8 April 2021

Published online: 30 June 2021

\section{References}

1. Miller AC. Opinions on the legitimacy of death declaration by neurological criteria from the perspective of 3 Abrahamic faiths. Medeni Med J. 2019;34(3):305-13.

2. District of Columbia. Determination of death (Uniform Determination of Death Act of 1981); natural death (Natural Death Act of 1981). Lexis DC Code DC. 1982;Sect. 6.24016 .2421 to 6.2430 amended Feb 1982.

3. Brugger ECD. Alan Shewmon and the PCBE's white paper on brain death: are brain-dead patients dead? J Med Philos. 2013;38(2):205-18.

4. Miller FG, Truog RD. The incoherence of determining death by neurological criteria: a commentary on "controversies in the determination of death", a white paper by the President's Council on Bioethics. Kennedy Inst Ethics J. 2009;19(2):185-93.

5. Wijdicks EF. The transatlantic divide over brain death determination and the debate. Brain. 2012;135(Pt 4):1321-31.

6. Gostin LO. Legal and ethical responsibilities following brain death: the McMath and Munoz cases. JAMA. 2014;311(9):903-4. 
7. Choong KA, Rady MY. Re a (a child) and the United Kingdom code of practice for the diagnosis and confirmation of death: should a secular construct of death override religious values in a pluralistic society? HEC Forum. 2018;30(1):71-89.

8. Bibler TM, Galbraith KL, Brothers KB. Ethics and brain death in pediatrics: recent controversy and practical suggestions. J Pediatr Intensive Care. 2017:6(4):240-4.

9. Yanke G, Rady MY, Verheijde JL. In re guardianship of Hailu: the Nevada Supreme Court casts doubt on the standard for brain death diagnosis. Med Sci Law. 2017;57(2):100-2.

10. Busl KM. What does the public need to know about brain death? AMA J Ethics. 2020;22(12):E1047-54.

11. Lewis A, Lord AS, Czeisler BM, Caplan A. Public education and misinformation on brain death in mainstream media. Clin Transplant. 2016;30(9):1082-9.

12. Lewis A, Weaver J, Caplan A. Portrayal of brain death in film and television. Am J Transplant. 2017;17(3):761-9.

13. Daoust A, Racine E. Depictions of "brain death" in the media: medical and ethical implications. J Med Ethics. 2014;40(4):253-9.

14. Siminoff $L A$, Burant $C$, Youngner SJ. Death and organ procurement: public beliefs and attitudes. Soc Sci Med. 2004;59(11):2325-34.

15. Franz HG, DeJong W, Wolfe SM, et al. Explaining brain death: a critical feature of the donation process. J Transpl Coord. 1997;7(1):14-21.
16. Kerridge $\mid H$, Saul P, Lowe M, McPhee J, Williams D. Death, dying and donation: organ transplantation and the diagnosis of death. J Med Ethics. 2002;28(2):89-94.

17. Pelletier M. The organ donor family members' perception of stressful situations during the organ donation experience. J Adv Nurs. 1992;17(1):90-7.

18. Long T, Sque M, Addington-Hall J. Conflict rationalisation: how family members cope with a diagnosis of brain stem death. Soc Sci Med. 2008;67(2):253-61.

19. Lewis A, Adams N, Varelas P, Greer D, Caplan A. Organ support after death by neurologic criteria: results of a survey of US neurologists. Neurology. 2016;87(8):827-34.

20. Lewis A, Kitamura E. The intersetion of neurology and religion: a survey of hospital chaplains on death by neurological criteria. Neurocrit Care. 2021. https://doi.org/10.1007/s12028-021-01252-x.

21. Stricker $\mathrm{KH}$, Kimberger $\mathrm{O}$, Schmidlin $\mathrm{K}$, et al. Family satisfaction in the intensive care unit: what makes the difference? Intensive Care Med. 2009;35(12):2051-9.

22. Olick RS, Braun EA, Potash J. Accommodating religious and moral objections to neurological death. J Clin Ethics. 2009;20(2):183-91.

23. Greer DM, Shemie SD, Lewis A, et al. Determination of brain death/ death by neurologic criteria: the World Brain Death Project. JAMA. 2020;324(11):1078-97. 